\title{
Severe complication of early cessation of therapy with ticagrelor after drug-eluting stent implantation
}

\author{
Natasha Ahmed ${ }^{1}$, Bartłomiej Perek ${ }^{2}$ \\ ${ }^{1}$ Student Scientific Group, Poznan University of Medical Sciences, Poznan, Poland \\ ${ }^{2}$ Department of Cardiac Surgery and Transplantology, Poznan University of Medical Sciences, Poznan, Poland
}

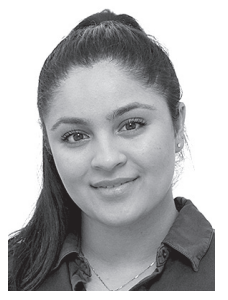

Kardiochirurgia i Torakochirurgia Polska 2021; 18 (2): 119-120

Anti-platelet agents are commonly prescribed after cardiovascular events, including acute coronary syndromes (ACS). One of them is ticagrelor, a drug that inhibits ADP-mediated P2Y12 dependent platelet activation and aggregation [1]. It is given in the secondary care of ST-segment elevation myocardial infarction (STEMI) with a percutaneous coronary intervention $(\mathrm{PCI})$ or in patients with non-ST-segment elevation myocardial infarction (NSTEMI). Of note, it is not recommended as monotherapy within the first 3 months after $\mathrm{PCl}$ but in addition to aspirin [2,3]. Dual antiplatelet therapy (DAPT) is of paramount importance during this particular time, known as the reendothelialization period [4]. Afterwards, ticagrelor should be considered in monotherapy in NSTEMI patients with low bleeding risk after percutaneous procedures (class of recommendation Ila) [3]. In the letter to the Editor, a case of serious consequences of ticagrelor cessation a few days after angioplasty followed by drug-eluting stent (DES) implantations is described.

A 52-year-old man was admitted urgently with unstable angina. His medical history included hypertension, diabetes mellitus, obesity, and a prior STEMI. The latter occurred 12 years ago and was treated with bare-metal stent (BMS) implantation to the right coronary artery (RCA), which required repeat intervention 4 years later. For the current angina symptoms, an urgent coronary angiography was performed, revealing complete occlusion of the RCA at the distal segment (Figure $1 \mathrm{~A}$ ) along with significant stenosis in the left anterior descending and left circumflex arteries. Subsequently, $\mathrm{PCl}$ was conducted, and two drug-eluting stents (DES) (Angiolite) $3.5 \times 19$ (iVascular, Barcelona, Spain) and Alex Plus $4.0 \times 22$ (Balton, Warsaw, Poland)) which contained sirolimus were implanted (Figure $1 \mathrm{~B}$ ). The patient was discharged on the afternoon of $31^{\text {st }}$ December 2020 with a $90 \mathrm{mg}$ prescription of ticagrelor. However, due to lack of availability in the nearest pharmacy, the patient did not take it and unfortunately $22 \mathrm{~h}$ later, was re-admitted urgently. He presented with acute chest pain which radiated to the upper extremities and jaw. On the ECG, ongoing myocardial infarction of the posterior wall was noted. In the emergency coronary angiography, acute thromboses in the previously implanted stents were found (Figure $1 \mathrm{C}$ ), thromboembolic material was removed by means of a device by manual thrombectomy, and numerous inflations using angioplastic balloons (NC $2.5 \times 18$, then $3.5 \times 15$ and eventually $4.0 \times 15$ ) were performed successfully (Figure $1 \mathrm{D}$ ). The ejection fraction (EF) of the patient had reduced from $45 \%$ estimated during the initial hospitalization to $30 \%$ once he was readmitted. The further clinical course was uneventful. Currently, 2 months after readmission his clinical status is relatively good. Since the last hospitalization he has not presented anginal symptoms although his functional status estimated according to NYHA classification has been improving slowly.

This case is unique because there is a $0-3.1 \%$ risk of early stent thrombosis [5]. Drugs such as sirolimus induce tissue factor in the stented lesion which can activate the coagulation system [6]. It must be stressed that our case was of high risk due to previous stent implantation at a very young age (approximately 40 years). However, the two doses of antiplatelet medication that were not taken could have caused the aforementioned effects. Ticagrelor represent the same group of drugs as clopidogrel; however, due to the high risk of bleeding, it is reserved as secondary management [2]. This P2Y12 inhibitor is, therefore, reserved for patients with major ischemic events, advanced atherosclerosis, and recurrent atherothrombotic coronary events [7]. It is obvious why our patient was initially put on this medication: because of the aggressive form of coronary atherosclerosis, his prior MI and stent placement in 2009 that had to be inspected again 4 years after. Although the patient is at fault for his noncompliance regarding antiplatelet agents, physicians need to make sure people are discharged with an appropriate amount of medication. Despite implantation of a DES, cardiologists cannot rely purely on the patient accountability and should ideally give them a few doses after discharge; this will be particularly useful during holiday periods. Another reason for ticagrelor treatment cessation may be the socioeconomic status of many patients in Poland. The statistics show that as many as $30-40 \%$ of patients on ticagrelor or prasugrel switch to clopidogrel due to such reasons.

Address for correspondence: Bartłomiej Perek MD, PhD, Department of Cardiac Surgery and Transplantology, Poznan University of Medical

Sciences, 1/2 Dluga St, 61-848 Poznan, Poland, e-mail: bperek@ump.edu.pl

Received: 7.03.2021, accepted: 13.03.2021. 


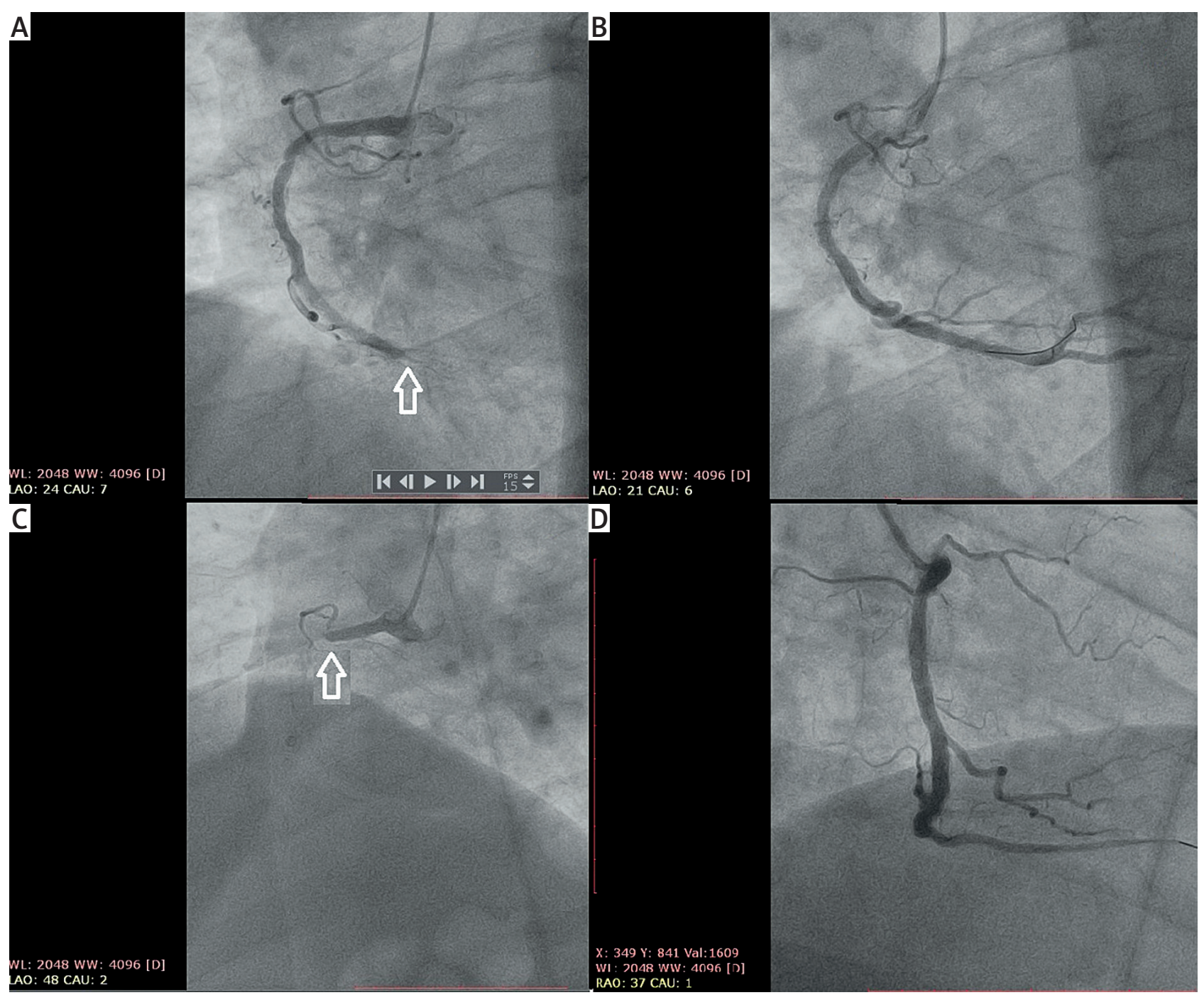

Figure 1. Right coronary artery (RCA) view in two coronary angiographic examinations, the first one (A and B) done on December $29^{\text {th }}$ and the second one $(\mathbf{C}$ and $\mathbf{D})$ done urgently during acute coronary syndrome on January $1^{\text {st }}$. The primary intervention for distal occlusion of the RCA (white arrow) (A) was successful (B). A few days later, the RCA was completely obstructed, this time in the proximal segment (white arrow) (C), and again angioplasty was successful (D)

In conclusion, this article highlights, in our opinion, the underestimated problem of patients' non-compliance with the physician's recommendations. Some of its consequences may be asymptomatic, but others, as in our case, can lead to life-threatening adverse events.

\section{Disclosure}

The authors report no conflict of interest.

\section{References}

1. Husted S, van Giezen JJ. Ticagrelor: the first reversibly binding oral P2Y12 receptor antagonist. Cardiovasc Ther 2009; 27: 259-74.

2. Mehran R, Baber U, Sharma SK, Cohen DJ, Angiolillo DJ, Briguori C, Cha JY, Collier T, Dangas G, Dudek D, Džavík V, Escaned J, Gil R, Gurbel P, Hamm CW,
Henry T, Huber K, Kastrati A, Kaul U, Kornowski R. Ticagrelor with or without aspirin in high-risk patients after PCI. N Engl J Med 2019; 381: 2032-42.

3. Collet JP, Thiele H, Barbato E, Barthélémy O, Bauersachs J, Bhatt DL, Dendale $P$, Dorobantu M, Edvardsen T, Folliguet T, Gale CP, Gilard M, Jobs A, Jüni P, Lambrinou E, Lewis BS, Mehilli J, Meliga E, Merkely B, Mueller C, Roffi M, Rutten FH, Sibbing D, Siontis GCM; ESC Scientific Document Group. 2020 ESC Guidelines for the management of acute coronary syndromes in patients presenting without persistent ST-segment elevation. Eur Heart J 2021; 42: 1289-367.

4. Song JW, Soh S, Shim JK. Dual antiplatelet therapy and non-cardiac surgery: evolving issues and anesthetic implications. Korean J Anesthesiol 2017; 70: $13-21$.

5. Cook S, Windecker S. Early Stent Thrombosis. Circulation 2009; 119: 657-9.

6. Lüscher TF, Steffel J, Eberli FR, Joner M, Nakazawa G, Tanner FC, Virmani R. Drug-eluting stent and coronary thrombosis. Circulation 2007; 115: 1051-8.

7. Bonaca MP, Bhatt DL, Cohen M, Steg PG, Storey RF, Jensen EC, Magnani G, Bansilal S, Fish MP, Im K, Bengtsson O, Ophuis TO, Budaj A, Theroux, Ruda M, Hamm C, Goto, S, Spinar J, Nicolau JC, Kiss RG. Long-term use of ticagrelor in patients with prior myocardial infarction. N Engl J Med 2015; 372: 1791-800. 